\title{
A CONCEPTUAL MODEL ANALYSIS OF SST INFLUENCE ON MARINE BIOTA IN THE SOUTH JAVA SEA
}

\author{
Albert Sulaiman ${ }^{*}$ and Nani Hendiarti \\ Center of Technology for Natural Resources Inventory \\ Agency for the Assessment and Application of Technology \\ BPPT new bldg $19^{\text {th }}$ floor, Jl. MH Thamrin 8 Jakarta, 10340 \\ *albertus.sulaiman@bppt.go.id
}

\begin{abstract}
We developed a conceptual coupled atmosphere-ocean-ecosystem model for the South Java seas to investigate interaction between marine biota and SST variability due to monsoon-forced. Ocean and atmosphere are represented by a box model for one dimensional water column. The equation of motions of the zonal wind stress and SST are represented in term of nonlinear oscillator model. Marine biota are represented by three components (nutrient, phytoplankton and zooplankton) of NPZ Edward-Brindley model. The marine ocean-atmosphere coupling mechanism is done through the absorption of blue light by phytoplankton. The system of nonlinear dynamical equation is solved by using Matlab ODE solvers. Monthly SST data is used to compare the model. Result showed that the period and amplitude of oscillation of SST and ecosystem component strongly depend on the parameter choice which describes the dynamical characteristic of the system. The SST and ecosystem variability will strongly correlate with monsoonal wind if we choose the parameter of light attenuation by water $0.2 \mathrm{~m}^{-1}$. Strong seasonal variations associated with monsoonal winds were observed for SST, phytoplankton and zooplankton concentration. On the other hand, the nutrient concentration shows a weak seasonal variation
\end{abstract}

Keywords: SST, NPZ, monsoon, delayed oscillator

\section{INTRODUCTION}

It's well known that the dynamics of ocean and atmosphere is a very complicated phenomenon. The complexity and nonlinearity of the ocean-atmosphere interaction for example, pose great difficulties for theoretician to explain in the simple models. Consequently, numerical model such as general ocean circulation model based on the supercomputer apparatus have been developed in recent decades. At the same times the development of theoretical nonlinear dynamical system and the progress of the intensive observation showed that quasi- periodic behavior of oceanic and atmospheric parameter. Theoretical studies of the properties of the coupled ocean and atmosphere in terms of nonlinear dynamical system have been investigated by several scientists (Wang and Fang 1996; Tziperman et al., 1995; Eccles and Tziperman, 2003). The studies use various simple delay oscillator models and other simple nonlinear model and analyses the model using nonlinear dynamical system theory such as phase space construction, circle map and possibility quasi-periodicity route to chaos. The studies showed that the natural oscillation of the equatorial Pacific coupled ocean-atmosphere system can enter into nonlinear resonance with the seasonal cycle at several period of the oscillator (Suarez and Schops, 1988; Tziperman et al., 1995; Liu, 2001).

The influence of phytoplankton on the tropical Pacific heat budget may exist. The study was done by (Marzeion et al., 2005) where they used a hybrid coupled model for the tropical Pacific i.e. a 
primitive equation reduced-gravity multilayer ocean model, a dynamic ocean mixed layer, an atmospheric mixed layer, and a statistical atmosphere. The result showed the bioclimate feedback was diagnosed. The diagnosed was based on the result that a maxima of the subsurface chlorophyll concentrations lead to an enhanced subsurface warming due to the absorption of photo synthetically through shortwave radiation.

Oscillation phenomena of marine biota has been predicted by nutrient, phytoplankton and zooplankton model (NPZ model) (Edward and Brindley, 1999). The model consists of three coupled ordinary differential equation and running under summertime physical condition. The result showed that the oscillation occur across broader ranges of parameters for the linear mortality function than the quadratic one. The chaotic behavior also observed when the higher predation on zooplankton was changed (Edward and Brindley, 2009; Edward, 2001).

Relation between marine environment and marine biota via oscillation phenomena observed by quantification of the feedback between phytoplankton and ENSO (Jochhum et al., 2009) and also relationship of chlorophyll a with climatic factor (Villate et al., 2008). Recent development of the area was done by Heinemann et al (Heinemann et al., 2011). The physical model used is an extended version of Jin's nonlinear ENSO recharge model with coupling with marine biota through the absorption of blue light by phytoplankton. Marine biota is represented by NPZ model developed by Edward and Brindley (1996). The result showed that bio-physical coupling may play a considerable role in modulating ENSO variability.

In the paper we used the same method of Heineman et al. (2011) to simulated biophysical coupling i.e. Sea
Surface Temperature (SST) and biomass in the South Java Sea (SJC). The Asian monsoon has a dominant influence on SST variation in the SJS (Qu et al., 2005). The variation is about more than 4.0 with the temperature minima at August when the southeast monsoon prevails. The low SST at August is caused by upwelling phenomenon and strongly correlated with ENSO (Susanto and Gordon, 2005). Previous studies showed that SST decreases on July to September but chlorophyll a increase (Hendiarti et al., 2005; Susanto and Marra, 2005). This cooling effect and increasing of phytoplankton growth in the coastal area on SJS is caused the upwelling during this period (Hendiarti et al., 2005). They also showed an increasing of a pelagic caught at this season. Using this fact, there is an indication of a strong coupling between SST variation and marine biota at SJS.

The paper develops a simplified model of marine environment that is represented by a nonlinear delayed oscillator model and marine biota by NPZ model. The coupling between marine environment and marine biota is studied through the absorption of blue light by phytoplankton. In Sec.2 the model is introduced and dynamical analysis is done in Sec.3. The paper will be ended by a summary.

\section{METHOD}

\subsection{Ocean Model}

The variation of SST in the SJS is also influence by equatorial Kelvin wave that generated in the central Indian Ocean. The Kelvin wave propagate along Java coast and push the thermocline down and hence increase SST variation $(\mathrm{Qu}$ et al., 2005). The ocean model should be built on interaction between SST and the wind stress. The feedback mechanism is represented by a nonlinear term and the atmospheric term is represented by the 
net heating of the surface mixed layer. Therefore, the conceptual (theoretical) ocean model is given by (Wang, 2001),

$$
\begin{aligned}
\frac{d T}{d t} & =\frac{Q_{n e t}}{\rho c_{p} H}+a_{1} \tau-a_{2} \tau(t-\eta)-\varepsilon T^{3} \\
\frac{d \tau}{d t} & =r_{1} T-r_{x} \tau
\end{aligned}
$$

where T is SST anomaly, $\tau$ is wind stress anomaly in South Java Sea and $t$ is time. The coefficient of a (positive feedback) and $b$ (negative feedback) are positive constant, $\varepsilon$ is a cubic damping coefficient, $c_{p}$ is heat capacity of the mixed layer $\left(1.053 \mathrm{e}^{8} \mathrm{~J} \mathrm{~kg}^{-1} \mathrm{~K}^{-1}\right), \rho$ is sea water density $\left(1024 \mathrm{~kg} \mathrm{~m}^{-3}\right), \eta$ is Kelvin wave period, $\mathrm{Q}_{\text {net }}$ is net heat flux, $\mathrm{H}$ is well-mixed surface layer depth, $r$ is positive coefficient and $r_{x}$ is damping coefficient of wind stress. (note: in Wang (2001) $\eta$ is a time for waves to travel to the western to eastern boundary of pacific Ocean). We have added new term (first term) in the right hand side of the first equation to explore influence of phytoplankton in the upper ocean through the heat budget. The study has been done by ref. Marzeion (2005) in the study of biophysical feedback in the Tropical Pacific. The equation (1) is called the delayed oscillator model that usually describes ENSO variation. The physics of Eq. (1) is the delayed oscillator, but the mathematical form is different from the original delayed oscillator (Suarez and Schoff, 1988). This system considers the variations of the SST anomalies and the variations of the zonal wind stress anomalies. The atmospheric zonal wind stress anomalies induce the variations of the SST anomalies that in turn affect the zonal wind stress anomalies. It is the interactions between the oceanic and atmospheric variables associated with equatorial wave dynamics that form the coupled system (Wang, 2001).

\subsection{Biota Model}

The marine biota of the South Java Sea is represented by a simplified ecosystem model that has three components: nutrient $(\mathrm{N})$, phytoplankton (P) and zooplankton ( $\mathrm{Z}$ ). The model is proposed by Steele and Handerson (1981) and modified by Edwards and Brindley (1996). Here, we use Edward and Brindley (EB96) model as follow (Edward and Brindley, 1999; Heinemann et al., 2011),

$\frac{d N}{d t}=-\frac{N}{e+N} \frac{a}{k_{w}+k_{c} P} P+r P+\frac{\beta \lambda P^{2}}{\mu^{2}+P^{2}} Z+\gamma q Z^{2}+k\left(N_{0}-N\right)$

The first term in the right hand side is represent the uptake of nutrient, the second term recycling of $P$, the third excretion of $\mathrm{N}$ by $\mathrm{Z}$, the fourth recycling of $\mathrm{Z}$ and the last term is upwelling. Phytoplankton also has five terms that represent uptake, respiration, grazing, sinking and upwelling. Zooplankton act as a predator has two term i.e. growth and higher predation and natural mortality. The equation of phytoplankton and zooplankton is given by,

$\frac{d P}{d t}=-\frac{N}{e+N} \frac{a}{k_{w}+k_{c} P} P-r P+\frac{\lambda P^{2}}{\mu^{2}+P^{2}} Z-s P-(s+k) P$

$\frac{d Z}{d t}=\frac{\alpha \lambda P^{2}}{\mu^{2}+P^{2}} Z-q Z^{2}$

The default value of parameter relevant for the model (Edward and Brindley, 1999): $\mathrm{q}=0.11$ is higher predation on $\mathrm{Z}$ (day $\left.^{-1}\right), a=0.2$ is growth rate coefficient $\left(\mathrm{m}^{-1}\right.$ day $\left.^{-1}\right), \quad k_{w}=0.2$ light attenuation by water $\left(\mathrm{m}^{-1}\right), \quad k_{c}=0.4$ is biomass-specific attenuation coefficient (m2 (gC) $\left.)^{-1}\right)$, $e=0.03$ half-saturation constant for $\mathrm{N}$ uptake $\left(\mathrm{g} \mathrm{C} \mathrm{m}^{-3}\right), \mathrm{k}=\mathrm{w} / \mathrm{H}=0.05$ is crossthermocline exchange rate $\left(\right.$ day $\left.^{-1}\right), r=0.15$ is $\mathrm{P}$ respiration rate $\left(\right.$ day $\left.^{-1}\right), \quad s=0.04$ is sinking lost rate $\left(\right.$ day $\left.^{-1}\right), \quad N_{o}=0.6$ is concentration below mixed layer $\left(\mathrm{g} \mathrm{C} \mathrm{m}^{-3}\right)$ 
, $\alpha=0.25$ is $\mathrm{Z}$ growth efficiency, $\beta=0.33$ is $\mathrm{Z}$ accretion fraction, $\gamma=0.5$ is regression of $\mathrm{Z}$ predation accretion, $\lambda=0.6$ maximum $\mathrm{Z}$ grazing rate $\left(\right.$ day $\left.^{-1}\right)$ and $\mu=0.035$ is $\mathrm{Z}$ grazing half-saturation coefficient ( $\mathrm{g} \mathrm{C} \mathrm{m}^{-}$ ${ }^{3}$ ). Dynamical behavior of NPZ model can be seen in Edward and Brindley (1999).

\subsection{Interaction Term}

The coupling between physical (ocean) model and biological (biota) model trough solar shortwave radiation and upwelling. An increase of the incoming shortwave radiation causes higher phytoplankton concentration and the concentration of nutrient is strongly influenced by the upwelling rate $(k)$ (Heinemann et al., 2011). In the other hands, marine biota can affects the physical system via the absorption of blue light by phytoplankton then it can induce intraseasonal SST variation (Gildor et al., 2003). The phytoplankton absorption coefficient per unit of chlorophyll concentration is a key factor in light propagation within ocean and relation of the chlorophyll-specific absorption coefficient with the chlorophyll-a concentration is not linear (Nababan, 2009). It means that there is no simple relationship between absorption of shortwave radiation, phytoplankton abundance, chlorophyll-a, nutrient-rich and physical system. For simplification, here assume that the phytoplankton concentration only attain non-zero value in the surface layer. The absorption coefficient $\left(k_{\alpha}\right)$ for blue light is given by (Heinemann et al., 2011),

$k_{\alpha}=k_{w}+k_{c} P$

In the sea water without biomass the value of $k_{w}$ is $0.046 \mathrm{~m}^{-1}$ (Heinemann et al., 2011). The high value of $k_{w}$ mean less of penetration of shortwave radiation then it increase the phytoplankton concentration. The dependency of phytoplankton concentration with the light attenuation coefficient $k_{c}$ is determines the feedback on the physical system. The relation with heat flux is given by,

$Q_{n e t}=(1-0.55) Q_{s w} e^{-k_{\alpha} H}$

where $Q_{s w}$ is net incoming shortwave radiation and we have ignored outgoing longwave radiation, sensible heat flux and latent heat of evaporation for simplicity. In the tropical region the annual mean value of $Q_{s w}$ is assume $420 \mathrm{Wm}^{-2}$ (Neelin, 1994). The effect of SST into marine biota is also influence by upwelling with relation (Jin, 1997)

$$
H=-\frac{w}{\zeta \tau}
$$

where $\mathrm{w}$ is vertical ocean current and $\zeta$ is upwelling efficiency.

\section{RESULT AND DISCUSSION}

\subsection{SST Variation}

The monsoon effect is investigated by applying a lowpass filter in SST data. We solve Eq.(1) by using Runge-Kutta scheme of ordinary differential equation that has been developed in Matlab 7.1. Using parameters $a_{1}=0.15 ; a_{2}=0.35 \mathrm{C} \mathrm{m}^{2}$ $N^{-1}$ month $^{-1} ; \varepsilon=0.015{ }^{\circ} \mathrm{C}$ month $^{-1}$; $r_{x}=0.02 ; \quad r_{1}=0.015$ and $\eta=0.35$, the result is depicted in Figure 1 . The sea surface temperature model compare with low pass filter of the sea surface temperature data from July 2004 to February 2009.

The result shows a strong monsoonal effect in the sea surface temperature and wind stress in that area. The result on wind stress simulation shows the amplitude attenuation where that condition is related to the amplitude attenuation of the SST. In the period of year 2005 and 2007, the result delivered from the model shows the delay of 
minimum curve about one month. The minimum SST which is usually occurs in August was shifted to October, however in the year 2008 the results from the model based on the data analysis are consistent. The minimum condition or a small depression of SST off Java and Sumatra is a results from internal and external factors. The external factor may influence by Indonesian Througflow (ITF) that transfer a large amount of warm, freshwater from Pacific to the Indian Ocean (Qu et al., 2005; Du et al., 2005).

\subsection{The Effect of SST on Marine Biota}

As mention above that the effect of SST on marine biota via solar incoming shortwave radiation and upwelling. The effect of shortwave radiation is represented by the absorption coefficient $\left(k_{\alpha}\right)$ for blue light. We run the model for sea water without biomass the value of $k_{w}$ and $\mathrm{Q}=0$ no heat flux where the result is depicted in Figure 2a.

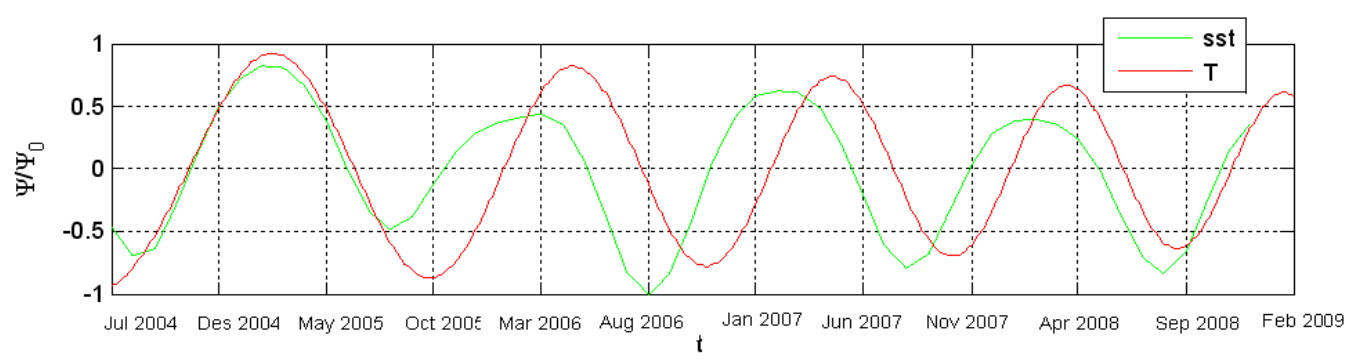

(a)

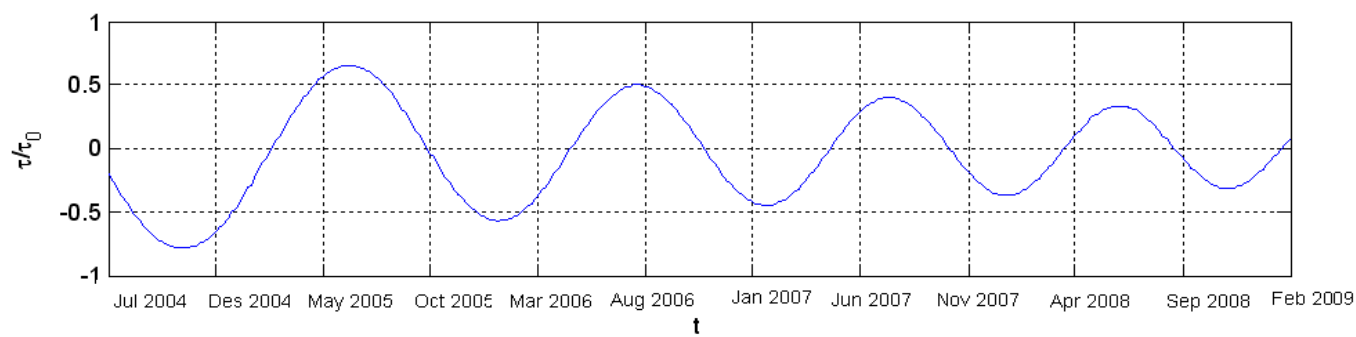

(b)

Figure 1. a) Comparison between lowpass filter SST (green) and SST of eq.(1) (red), b) wind stress of eq.(1).
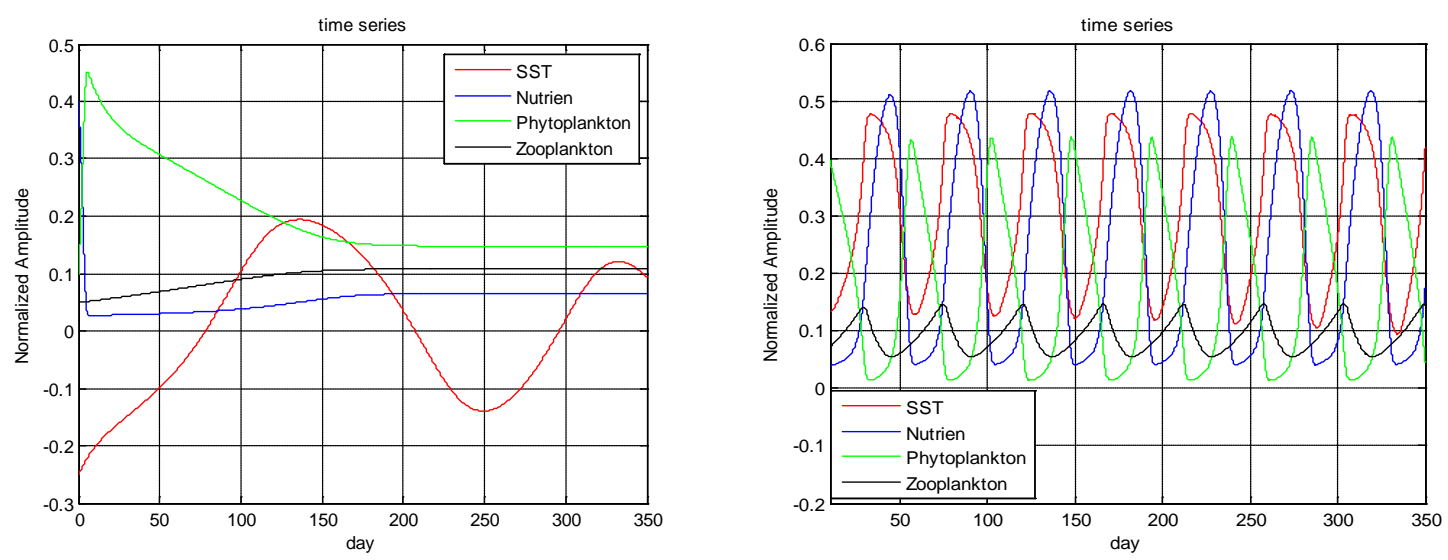

Figure 2. a) Time series of N, P, Z and SST when absorption coefficient is $k_{w}=0.046$ and $\mathrm{Q}=0$, b) time series of $\mathrm{N}, \mathrm{P}, \mathrm{Z}$ and SST when $\mathrm{kw}=0.2$ and $\mathrm{Q}=420$. 
Figure 2a shows the condition where there is no interaction between SST and biomass. The result delivered from the model shows the biomass will suffer becomes the asymptotically constant. If the absorption coefficient increase and heat flux are used thus the biomass will change into periodically pattern as well as the SST as a result from the interaction among both parameters (see figure $2 \mathrm{~b}$ ).

Furthermore, we also reviewed if the effects of upwelling were taken into account by an increase of upwelling efficiency twice it follows that the effect on the marine biota as shown in the Figure 3a. Upwelling influences the marine biota through the relation of $k_{c}=w / H$. If the absorption coefficient is increased two times become $k_{w}=0.4$ thus the results show in the figure $3 \mathrm{~b}$. It shows the significant impact, which is the increasing of nutrient concentration will be followed by the phytoplankton. Besides that, the oscillation period also became longer, which the previous condition with 50 days becoming 100 days. An increase of

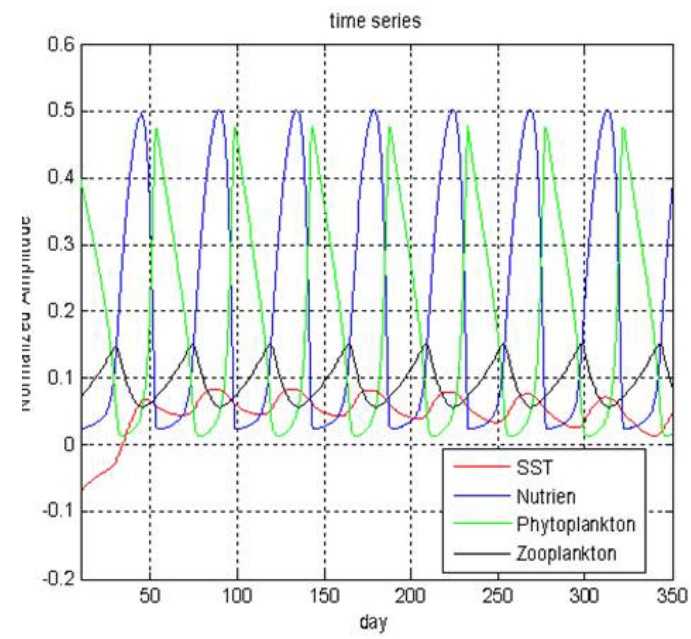

nutrient and phytoplankton will be also followed by decreasing of the SST. This fact shows the interaction between the SST and marine biota.

Finally, let we make an experiment with changing the higher predation on $\mathrm{Z}$ with $q=0.142$. The time series show very drastically pattern. The pattern is shown in Fig (4).

The pattern show typical behavior that is called chaotic dynamics. The phenomena occur when the higher predation on $\mathrm{Z}$ is large enough. The increasing of $q Z^{2}$ term in the equation (5) represents carnivore predation of zooplankton. This means that the mortality rate of carnivorous zooplankton increases and decreasing herbivore zooplankton. When the herbivore zooplankton decrease then the phytoplankton concentration increase and finally the growth of phytoplankton is unpredictable. The system is unstable and goes to catastrophic event. May it is called phytoplankton bloom.

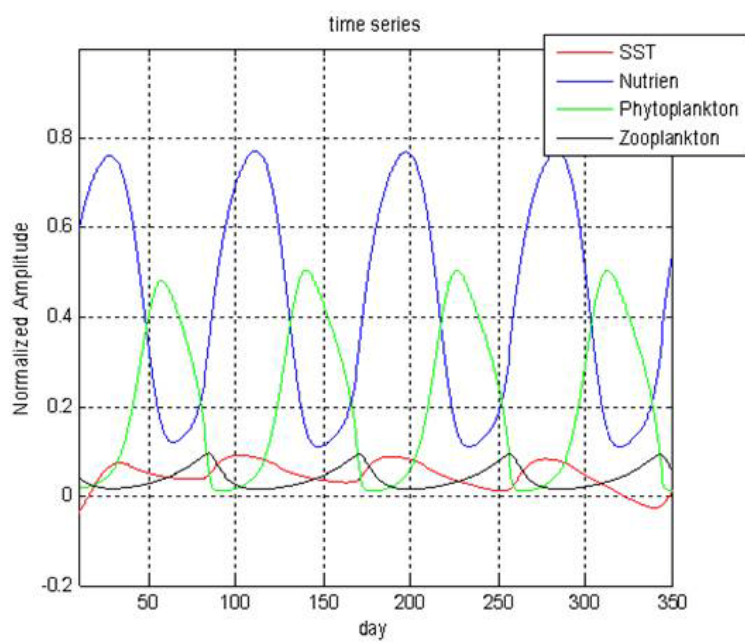

Figure 3. a) Time series of N,P,Z and SST when upwelling efficiency increase, b) time series of N,P,Z and SST when $\mathrm{kw}=0.4$ and $\mathrm{Q}=420$. 

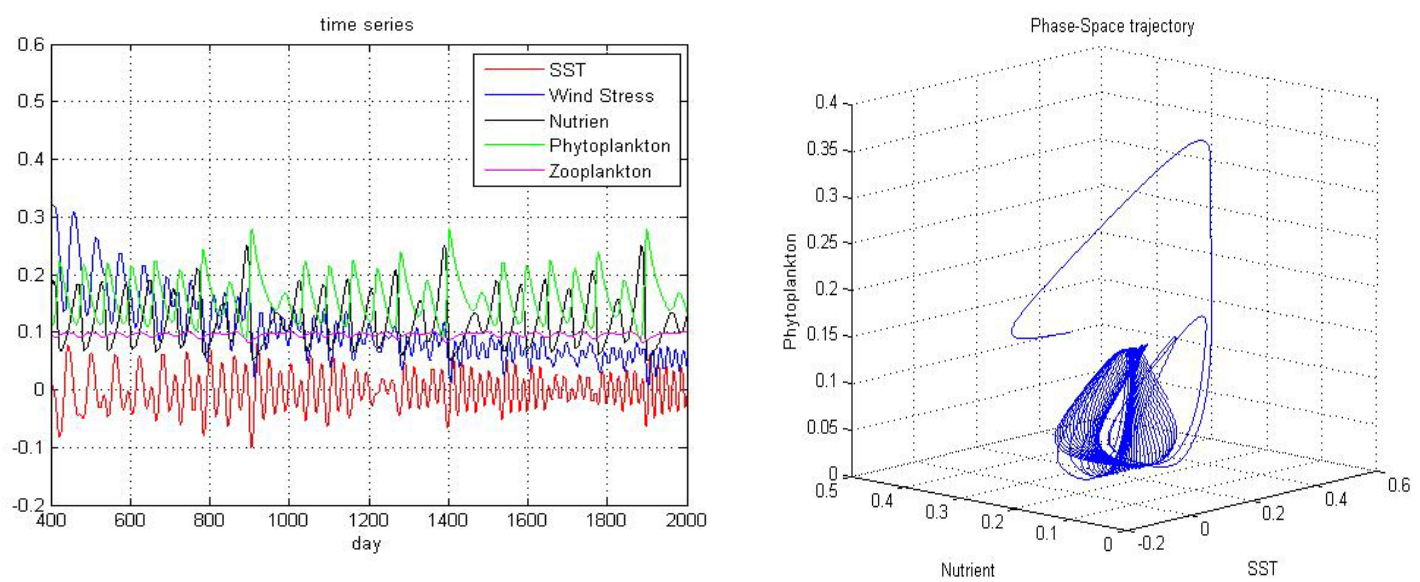

Figure 4. The time series and phase-space trajectory of chaotic phenomena of the coupling between marine biota (NPZ model) and marine environment (SST) with higher predation on $\mathrm{Z}, q=1.42$.

\section{CONCLUSION}

The conceptual coupled atmosphere-ocean-ecosystem model for interaction between marine environment and marine biota in the South Java seas has been investigated. The environment is represented by delayed oscillator model and the marine biota is represented by NPZ model. SST gives a significant influence to the marine biota with the condition of $k_{w}=0.2 \mathrm{~m}^{-1}$ and calculation of heat flux effect. Interaction between SST and marine biota is strongly affected by absorption coefficient $k_{w}$. If we increase parameter of higher predation on Z $(q)$ therefore the time series pattern of SST, nutrients, phytoplankton and zooplankton are not really periodic but quasi-periodic. The increasing of $q Z^{2}$ term that represents carnivore predation of zooplankton will caused the chaotic behavior of the system.

\section{Acknowledgement}

The research was supported by the Program Tematik TISDA 2011. Comments from an anonymous reviewer are also very helpful for improving the manuscript.

\section{REFERENCES}

Burgers, G., F.F. Jin, and G. J. van Oldenborgh. 2005. The simplest ENSO recharge oscillator. Geophys. Res. Letters, 0094-8276.

Du, Y., T. Qu, G. Meyer, Y. Masumoto, and H. Sasaki. 2005. Seasonal heat budget in the mixed layer of the southern tropical Indian Ocean in a high-resolution global general circulation model. J. of Geophys. Res., 110:C04012, doi:10.1029/2004 JC002845.

Eccles, F., and E., Tziperman. 2004. Nonlinear effact on ENSO's period. $J$. of the Atmospheric Science, 61:474-482.

Edward, A.M., and J. Brindley. 1999. Zooplankton mortality and the dynamical behaviour of plankton population model. Bulletin of Mathematical Biology, 61:303-339.

Edward, A. M. 2001. Adding detritus to a nutrient-phytoplankton-zooplankton model: a dynamical system approach. J. of Plankton Reseach, 23(4):389-413. 
Gildor, H., A.H. Sobel, M.A. Cane, and R.N. Sambrotto. 2003. A role for ocean biota in tropical intra-seasonal atmospheric variability. Geophysical Research Letters, 30(9):1460, doi:10.1029/2002GL 016759.

Heinemann, M., A. Timmermann, and U. Feudel. 2011. Interaction between marine biota and ENSO: a conceptual model analysis. Nonlinear Processes Geophysics, 18:29-40.

Hendiarti, N., Suwarso, E. Aldrin, K. Amri, R. Andiastuti, S.I. Sachomar, and I.B. Wahyono. 2005. Seasonal variation of pelagic fish cath around Java. Oceanography, 18(4):112-123.

Jin, F.F. 2001. Low-fequency modes of tropical ocean dynamics. J. of Climate, 14:3874-3881.

Jin, F.F. 1997. An equatorial ocean recharge paradigm for ENSO. Part I: conceptual model . J. of the Atmospheric Science, 54:811- 829.

Liu, Z. 2001. A Simple model study of ENSO suppression by external periodic forcing. $J$. of Climate, 14:1088-1098.

Marzeion, B., A. Timmermann, R. Murtugudde, and F.F. Jin. 2005. Biophysical feedbacks in the tropical pacific. J. of Climate, 18:58-70.

Nababan, B. 2009. Chlorophyll specific absorption coefficients and the impact of phystoplankton taxonomic group of surface waters in the Northeastern Gulf of Mexico. EJurnal Ilmu dan Teknologi Kelautan Tropis, 1(1):9-23.

Neelin, J. 1994. Dynamics of coupled ocean-atmosphere model: the tropical problem. Annu. Rev. Fluid. Mechanics, 26:617-59.

Qu, T., Y. Du, Yan, G. Mayer, and Y. Slingo. 2005. Sea surface temperature and its variability in the indonesian region. Oceanography, 18(4):50-61.

Suarez, M. and P.S. Schopf. 1988. A delayed action oscillator for ENSO. $J$. of the Atmospheric Science, 45(21):3283-3287.

Susanto, D. and A. Gordon. 2001. Upwelling along the coast of Java and Sumatra and its relation to ENSO. Geophysical Research Letters, 28:1,599-1,602.

Susanto, D. and J. Marra. 2005. Effect of the 1997/98 El Nino on chlorophyll a variability along the southern coast of Java and Sumatra. Oceanography, 18(4):124-127.

Tziperman, E., M. A. Cane, and S. E. Zebiak. 1995. Irregularity and locking to the seasonal cycle in an ENSO prediction model as explained by quasi-Periodicity route to chaos. J. of the Atmospheric Science, 52(3):293-307.

Villate, F., G. Aravena, A. Irriarte, and I. Uriarte. 2008. Axial variability in the relationship of chlorophyll a with climatic factor and the North Atlantic Oscillation in a Basque Coast estuary, Bay of Biscay (19972006). J. of Plankton Research, 30(9):1041-1049.

Wang, B., and Z. Fang. 1996. Chaotic oscillations of tropical climate: a dynamics system theory for ENSO. $J$. of the Atmospheric Science, 53(19):2786-2802.

Wang, C. 2001 . A unified oscillator model for the El Nino-Southern Oscillation. J. of Climate, 14:98115. 